\title{
Prerequisites for Customer Orientation
}

\author{
Erwin Schlögl, M.A. \\ University of Applied Sciences Burgenland
}

\begin{abstract}
A highly competitive global market means numerous opportunities as well as numerous threats and challenges. Products become increasingly indistinguishable. Companies need therefore to develop concepts and strategies for relationships with their customer. For this purpose, a comprehensive consideration is necessary. The shift from transaction marketing to relation marketing already took place, and the focus is on the customer. Customer relationship management seems to provide possible solutions for competitive markets. The CRM hype is ongoing even though failing CRM implementation rates of up to 75 percent are reported. One of the success factors for CRM implementation is orientation toward the customer. Customer orientation requires various different measures like change management, cross functional collaboration, process management, employee commitment and the support as well as the encouragement from the owners or investors of a company. Internal marketing is necessary to convince employees to switch from functional to cross functional thinking. Customer orientation is a strategy, a journey and a long-term undertaking and requires continuous review and improvement. This paper provides a comprehensive insight on necessary factors for customer orientation.
\end{abstract}

Keywords: CRM, customer orientation, change management, cross functional, process management,

JEL Classification: L61, M10, M15, M31

\section{Introduction}

In a complex environment of changing markets, very fast technological advances, and in which most information is available for everyone at any time, it is increasingly difficult for companies to establish a sustainable relationship with customers. Companies struggle to build sustainable relationships with loyal customers (Bruhn, 2016, pp. 3-4). Increasing competition leads to shorter market cycles, especially in challenging market situations. Companies need to calculate higher costs for development of new products due to increased requirements from customers as well as the complexity of new technology. There is a big challenge to generate profits with more complex products with shorter product life cycles. Thus, all costs must be covered within a shorter period of time. Companies strive to gain profits with innovation of new products, but it becomes more difficult to be successful because markets are saturated and customers very often skip development steps of products (Keuper, 2010, p. 9). Increased customer requirements and greater competition have an impact on customer relationships. Supply overtakes demand and the wide range of similar products in a global market exacerbates the trend towards variety seeking. Hence, the customer is in a strong position now. Furthermore, the communication between seller and buyer is also changing, not in the least because of different distribution channels (Schimmel-Schloo, 2007, p. 33).

The behaviour of customers has changed as well over the years. Customers are more familiar with new technology and they use this technology for more transparency. Moreover, they intend to be more flexible and variety seeking is a common trend. Fewer change barriers exist and this also supports variety seeking. In addition, customers appreciate the convenience of easy procurement from home without restrictions on opening hours (Schneider, 2008, pp. 1-2).

Arguments mentioned before induce firms to build relationships with customers or even to achieve customer loyalty. The shift from transaction marketing to relationship marketing has already occured. Transaction marketing puts the focus in most cases on the completion of the sale, whereas relationship marketing goes beyond one transaction (Schneider, 2008, p. 2).

The consideration of a customer relationship is often linked with monitoring the customer life cycle. Customer life cycle is a common marketing term which could lead to misunderstandings. In general, it explains the development of the customer 
relationship linked to a product. A termination of the relationship and thus the end of a customer life cycle means that the customer is not interested in a product anymore and might change to a competitor or another product for various reason (Winters, 2014, p.18).

\section{Customer Orientation}

Customer orientation as such has existed very long, even though it was only established as a fix term in 1950. Organisations need to focus on the customer, in order to compete successfully on the market (Ose, 2011, p. 27).

Although the organisations understand the importance of customer orientation, sustainable success is often missing, because management focuses on single topics like complaint management or implementation of a CRM software instead of an integrated approach (Bruhn, 2016, p.1).

All companies have at least one thing in common. They all have customers and thus they are all customer oriented. Customer orientation is obligatory, otherwise companies could not succeed on a competitive market. But it must be made clear that there is not just one market. A large number of different customers exists. Those customers have needs and a segmentation according to their needs will help to generate profit (Winters, 2014, p.18).

Customer orientation is a common trend and is thus announced often in various corporate designs. Nonetheless, customer orientation programs frequently fail during the implementation phase. As a result, the project often ends up without impact on real measures (Bruhn, 2016, p. 16).

The terms market orientation, marketing concept or customer first can be subsumed under customer orientation. For a successful and sustainable implementation of a customer orientation program a concept has to be developed (Nwankwo, 1995, p. 6). For a structured approach, companies have to know their customers, as well as their behaviour and their needs. Consequently, companies strive to fulfil customer needs. Successful companies develop strategies, whereby the customers can influence companies' product innovation, service setup, and decision-making process (Nwankwo, 1995, p. 8).

The fulfilment of customer needs was recognised as a main requirement since the emergence of the marketing concept at 1950s and 1960s. It was recommended to concentrate more on the needs of the customer and that all activities should be streamlined towards the customer. (Utzig, 1997, p. 1). Even though customer orientation is desirable, it is not recommended to consider customer orientation in isolation. Efficiency of customer orientation as well as costs have to be taken into account (Schimmel-Schloo, 2007 p. 35).

It is necessary to emphasize that customer orientation and the focus on customer relationship methods is always associated with costs. Firms should therefore determine, whether it would be worth the effort. Financial and human resources are limited within an organization. Hence it is necessary to find a way to optimize the treatment of customers. A distinction between good and best customers provide an overview of the environment and the potentials. Transparency thus helps to develop strategies to treat customers according their potential revenues. Profitable relationship customers should get more recognition than occasional customers. Customer equity is the value for the company and this value should be balanced with customer value which defines the customer value from the customer's perspective (Huldi, 2007, pp. 110-111).

As soon as unprofitable customers are identified, there must be a process in place to deal with them. One possibility is to cut expenses by reducing individual services for unprofitable customers. Furthermore, it should be considered to charge expenses for delivered services, which will not be charged to profitable customers. A strategy could be to try to increase sales with not profitable customers or try to get at least some recommendations for new customers from them. Finally, the waiver of turnover with unprofitable customers also needs to be taken into consideration (Huldi, 2007, p. 112). 
Following graphic shows the result of a customer survey (22.01.2016 - 05.02.2016) carried out in Austria.

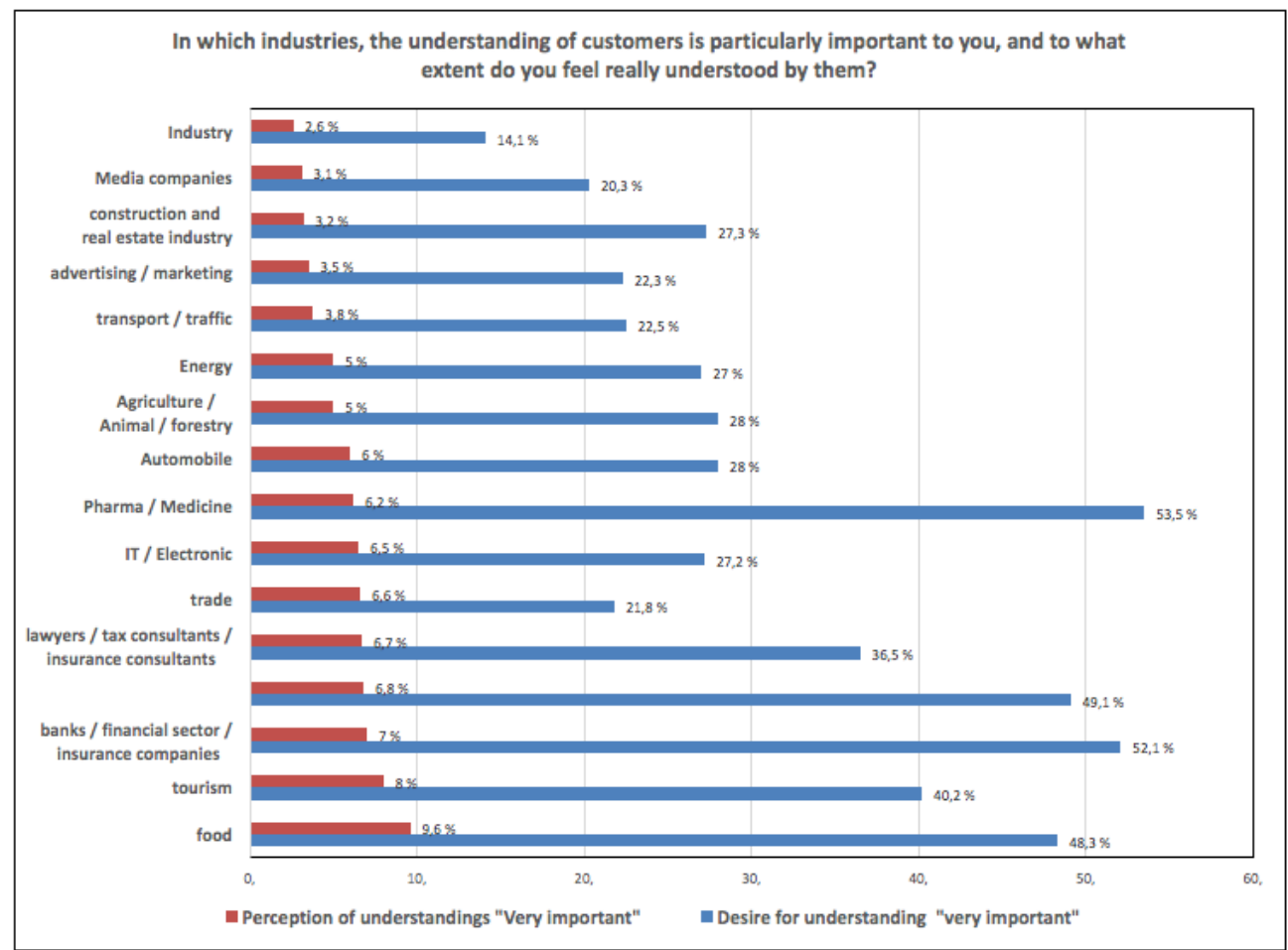

\section{Ref: Marketagent: Strategie Austria, Statista 2017, ID: 547256}

The chart shows that there are considerable deviations in industries regarding customer expectations regarding customer care. From the customer's perspective the pharmaceutical, medical , finance and insurance industries as well as food and luxury food are industries where customer orientation is considered particularly important. Significant is the very small percentage of customers who feel well understood by companies across all industries. In a historical retrospective it can be demonstrated, that there were many changes regarding the orientation on the market. Companies therefore had to adapt to the requirements of the market over the last decades. In the 1950ies and 1960ies, there was a strong product orientation recognised. This was the time after the Second World War, and the demand exceeded supply. During this phase companies focused on production and on delivering according to demand. In the 1970ies there was a market orientation. The switch from seller to buyer market took place, and companies recognised that customers requested/expected/demanded different treatment. Also, different segments required different treatment. In the 1980ies there was the phase of competition orientation. Products became more and more comparable and the pressure from many competitors was bigger. Companies tried to work on their USP. In the 1990ies the phase of customer orientation started, where the customer requested individual treatment and companies identified the need of flexible reaction based on the demands of the customer. (Bruhn, 2016, pp. 4-6) 


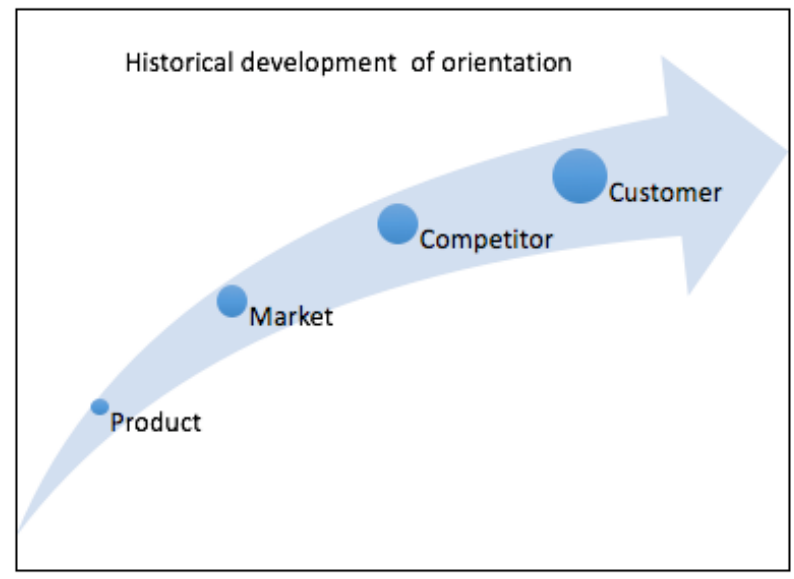

Adapted from Bruhn, 2016, pp. 7-8

The historical development shows furthermore the move from transaction marketing to relationship marketing over time. Companies were forced to rethink their strategies. Successful companies put the customer and his requirements first and not the product (Bruhn, 2016, pp. 7-8).

CRM could be one possible approach to support customer orientation. CRM promotes the optimizing of processes towards the customer and supports balancing and covering costs. CRM fosters the success of customer loyalty. All possible contact points with the customer must be transparent and available for all stakeholders within the company. All communication channels are then consolidated and as such are also transparent. Segmentation is a big task within a CRM project and thus also supports active customer orientation. Furthermore, CRM initiates segmentation of customers for different treatment of profitable customers and low-return customers. (Schimmel-Schloo, 2007 p. 34)

\subsection{Customer Segmentation}

Customers might be interested in a relationship with a company, because they trust the quality or service or they just focus on the cheapest price. Transaction customers are not interested in a relationship and can be easily identified by evaluation of buying behaviours from the past. Purchases made mainly within discount time frames are the main characteristic of transaction customers. (Newell, 2000, pp. 38-40)

Analysis prove that Pareto's law is right. According to Pareto's law, $20 \%$ of the customers (from one company) deliver 80 $\%$ of its revenues. This insight suggests installing different treatment for different customers. Especially profitable customers should get more attention and consideration, whereas the support for not profitable customers should be reduced to a minimum. After thorough analyses it might even be necessary to get rid of unprofitable customers (Newell, 2000, pp. 41 42).

Customer orientation is often linked to customer loyalty. Suppliers of CRM solutions claim that loyal customers are more profitable, because they deliver reference customers, they are less price sensitive and the treatment of loyal customers is cheaper than acquiring new ones. Unfortunately, it seems that this is very often not the case and companies should carefully check whether loyal customers are really profitable. A suggestion here is to differentiate between profitable loyal customers and others in their loyalty programs. The reason for a consideration of customers in regards to loyalty as well as profitability is the assumption that the connection between loyalty and profit is not as strong as companies believed. According to this finding, it turned out, that the stronger support for loyal customers is expensive and even loyal customers tend to buy goods from a competitor if a higher reduction in prices, rebates and discounts is possible. One method to differentiate customers is via the RFM method. RFM stands for recency, frequency and monetary value analysis. Recency describes customer purchases within the last 6,12 and more than 12 months. Frequency evaluates how often customers bought in each of the three timeframes. Scores for recency and frequency are added together. The higher the overall score is, the higher the customer is ranked. Thus, a segmentation can be made (Reinartz, Kumar, 2002, pp. 4-7). 
Another possibility to make a customer segmentation is to assign a customer to one of the four categories: Strangers, Butterflies, True friends or Barnacles. Strangers are a group of customers who are not loyal and not profitable. Therefore, it is not recommended to invest in them. Butterflies describes customers who are also not loyal but compared to Strangers profitable. The recommendation is here to benefit from them as long as possible, because they will only stay for a short period. The third group are True Friends. This customer group seems to be loyal and profitable. The last group are Barnacles. Those customers are very loyal but not very profitable. Recommendation is here to monitor those customers and try to improve their performance (Reinartz, Kumar, 2002 pp. 9- 10).

Customers should not be reviewed only with regard to their profitability and loyalty. A total consideration is necessary for successful companies. It is necessary to support and handle customers according to their profit and their loyalty - the whole picture is necessary (Reinartz, Kumar, 2002 p. 11).

\subsection{Change Management}

Whenever processes within an organization have to be changed, people are involved and their commitment is required to achieve the goals. Change management is a tool to support employees and prepare them for upcoming difficulties and challenges that may arise because of necessary changes (Schwarz, 2010, 509).

In times of changing and global markets with increased individual requirements, companies need to adapt quickly to upcoming trends. Rapid adjustment requires active participation from management as well as employees. Already established processes need to be adjusted. As an example, the involvement of E-Commerce into already existing systems is creating new efforts and changes within the company are necessary. Changes in the market as well as in customer needs require changes within companies. Existing behaviour of employees and management must be analysed and adjusted. Managers have to change their focus from lean management to a customer oriented future design (Künzel, 2002, pp. 5-8). A structured change management is thus necessary for existing challenges (Künzel, 2002, p. 9).

Business Process Reengineering (BPR) is one of several approaches of change management models. It was first mentioned in 1984. In this approach a new kind of process review is foreseen. Processes are reviewed cross functionally. Processes are analysed and question the value for the customer. Customer orientation is the main focus. As a consequence, processes need to be adjusted, outsourced or stopped (Künzel, 2002, pp. 12-13).

\subsection{Leadership / Management}

Leaders of a company are in charge to implement the vision of a company. Furthermore, leaders define the goals of its company and ensure that necessary resources are available to achieve the targets. Whenever changes on the market arise, and changes in customer needs are apparent, leaders have to react immediately to secure future growth of a company. Continuous review of progress based on the plan and taking immediate action if required is a main task of a manager. A customer orientation strategy of a company must be defined by top management. Successful implementation is only possible, if set up with top-down method. Leaders need to foster employees to see the potential coming from customers. Information and feedback from customers has to be seen as opportunity for a company. This behaviour enables the company to react quickly on the market and thus remain competitive. Involvement from leaders can help improve, for example, dealing with complaints and encourage employees to participate in the learning process. This behaviour ensures employees of top management's support (Gent, Kempster, 2002, pp. 64 -65).

Customer interests can be integrated proactively or reactively into decision mechanisms of a company. Proactively involving employees, because they are the touch point at point of sale. Management is encouraged to motivate their employees. Motivated employees provide benefit to the customer orientation program. Those employees should have/receive power and competences to solve problems quickly. An environment should be generated in which anticipating complaints and working on solutions instead of fire-fighting is desired. A natural reaction on complaints is usually a defensive behaviour of employees. Acting reactively means that customers do not get the necessary attention upfront. Another example for reactive management is to copy possible solutions for quick conflict handling from other organizations (Nwankwo, 1995, pp. 9-10).

The way companies are implementing and monitoring customer goals in their planning is unsatisfactory. The goals of an integrated customer strategy should be clear. In this regard the status quo of performance shall be evaluated. A permanent monitoring of the customer orientation, the development and the goals should be done. Furthermore, it is necessary to take measures for better tracking of the progress. Formal as well as informal measuring techniques can be carried out. Formal 
measurements are the monitoring of sales volume, profits or complaint analysis. Informal measuring is done, if standards are available, or standards exist, but not specified and can therefore not be measured (Nwankwo, 1995, pp. 10-11).

\subsection{Mission / Vision / Culture}

In times of change, moving targets and dynamic markets, a corporate vision may be helpful to stick to the goals. Frequent changes of the corporate vision should be avoided. Employees are frustrated if the corporate vision is obsolete following the change of management. SMEs can be used as models for long term goals, because their vision is designed for a long term without changes based on periodical trends (Künzel, 2002, p. 156).

The corporate mission statement describes principles of conduct and values of the company. Furthermore, it defines the customer orientation and how to deal with customers. This should help to create a team culture within the organisation (Hanning, Krumm 2010, p. 479).

A genuine mission statement is necessary to succeed in customer orientation. Printing posters with a mission explaining the importance of employees and being the greatest asset of a company is not enough. Top manager are responsible to walk their talk. It is insufficient to provide with rules, strategies and missions. In fact, all managers need to work as role models and support wherever possible to put all that into practice. Otherwise employees will not take it seriously. As a consequence, a gap will arise between the promised service to the customer and the delivered service. Managers should strive to build bridges between mission statement and service delivery (Pulse, Craven, 2002, pp. 75-76).

A corporate culture is identified on how employees and management collaborate, how they give and receive feedback, how they live a failure culture and how they deal with conflicts. Corporate culture is neither what is printed in bright colours on the walls of companies nor on posters in shops. Management should be aware that customers realize how employees collaborate and of course how they communicate internally and deal with other customers. In this regard, non-verbal behaviour shows more about the culture of a company than verbal behaviour. When customers feel that something is not coherent, they will reduce their buying activities as a consequence. Recurring trainings with employees could support resolving conflicts and improve the collaboration and appreciation between management and employees as well as among employees. Improvements here have immediate impact on customer care (Hanning, Krumm, 2010, p. 494).

Whenever there is a request for improvement of profit -the idea is quickly on the table to purchase a CRM software to solve problems. It is a valid method, but probably too early. The delivered outcome is then often not sufficient, because of the gap between the company strategy and the operative stage. Thus, employees get the feeling of pressure with the effect of undesired results. Motivated employees are more customer focused. They try to get input from customer. If employees are not familiar with the strategy of the company, they do not support the CRM strategy. The result is unsuccessful CRM projects (Winkelmann, 2007, p. 22-23).

\subsection{Employees}

Whenever customer orientation programs fail, the first reflex is to claim that employees do not fulfil the requirements for a successful implementation of customer orientation programs. For a successful participation of employees, it is necessary to set up an integrated approach, provide an adequate corporate culture upfront and appropriate processes. That means managers have to prepare an appropriate environment and this starts within the company (Bruhn, 2002, pp. 18-19).

Management of organizations show commitment towards employees and communicate the importance of employees for customer relationships, but employees are very often not involved in a CRM project. As a consequence, companies have to realize, that customer orientation is a joint task for all involved departments. In the past it was mainly the competence of the front office like marketing, sales, but findings show that all processes need to be aligned and managed synchronously with the aim of a greater external coherence. This approach is getting more attention because of developments due to multi-channel challenges (Schneider, 2008 pp. 4).

\subsection{Processes}

Customer orientation is a process that needs to be anchored across all departments of a company. This is often a change process. Within this process, employees need to be trained, motivated and instructed to be prepared for interaction with the customer. For a successful implementation of a customer orientation process, management needs to be aware that the 
endeavours require long-term planning. In parallel, it is necessary to monitor and permanently evaluate affected processes. Regular surveys with all customers can contribute to a successful journey (Michael Brendel, 2002, p.102).

Organizations need to rethink their corporate structure, because an orientation on the customer requires a fundamental change of existing processes. Usually companies have a product orientated process design installed. An intensive analysis of corporate processes is compulsory and should be executed as one of the first steps of a change towards customer orientation. consistent orientation towards the customer requires efficient processes that deliver value to the customer. For this purpose, it is necessary to start with the status quo. Business processes have to be analysed accordingly. Improvement of processes will adjust procedures within an organization. Thus, it will support a CRM strategy. The real objective is to develop corporate processes in regards of quality time and costs (Jaeck et al., 2007, p. 55-56).

A structured process for a process optimization can be described as follows:

\subsubsection{Goal definition / organisation}

First step should be a clear definition of the goal. A clear definition of the expected outcome of changed processes should be described. For an increase in customer satisfaction for example, a defined goal might be the reduction of processing times for customer requests or complaints (Jaeck et al., 2007, p. 57-58).

\subsubsection{Process-selection and Process survey}

Relevant processes must be identified, which will be analysed afterwards. For this purpose, only processes with direct impact on the customer should be taken into consideration (Jaeck et al., 2007, p. 58).

\subsubsection{Evaluation of processes}

All existing and also prospective customers and underlying processes must be analysed (Gaitanides et al., 1994, pp. 210211). It is not possible to evaluate all company processes, because of time and resource constraints. Therefore, it is necessary to find a way to identify critical processes. One possible method is to examine critical processes toward the customer with appropriate questions (Hammer,Champy, 1994, pp. 159-162).

Problematic processes can be identified with surveys sent to customer. The idea is to check their satisfaction with various processes and to identify most important processes with direct impact on the customer. Critical processes are marked as important by customers and where customers are not satisfied (Jaeck et al., 2007, p. 59).

Prerequisite for a qualitative analysis of processes is either a detailed documentation of the processes or the support of experts within the company who are willing to contribute. Those people could be asked at an early stage and they should be invited to provide their expertise. This procedure will also motivate key people (Jaeck et al., 2007, p. 60).

\subsubsection{Process design.}

Transparency of processes is necessary and can be delivered with process mapping. This way it is possible to get an overview of relevant processes and identify possible improvements easily. Thus, duplication of work or media disruptions can be detected. A process mapping will also support a CRM implementation afterwards (Jaeck et al., 2007, p. 61).

\subsubsection{Process analysis and improvement.}

Processes can be evaluated differently. One possible method is to evaluate processes according results, such as profit. Even though results are of utmost importance, it is difficult to directly identify a specific process to the result. It is, for example, difficult to assign the impact of customer satisfaction to a specific process. A clear assignment from isolated processes to global processes is thus difficult. It is easier to evaluate process sequences or the structure of the organization and determine the impact on results (Kreysch 1999, p. 870). Improvements of processes have to be assessed with regard to effectivity and efficiency, because processes could be very lean and optimized, but may nonetheless not lead to the desired result. Customer relationship management may therefore focus on process efficiency and could be measured with customer satisfaction (Jaeck et al., 2007, p. 63).

Customer satisfaction can be measured with information gathered in direct communication with the customer. Open questions are supposed to deliver information about customer satisfaction, dissatisfaction in the past, as well as suggestions from customer about possible improvements in the future. Direct input from the customer has to get greater 
attention than internal analysis of processes. Hence, if customers are not satisfied with specific processes even though internal evaluation state the contrary, processes have to be improved (Rosenkranz, 2002, S97). The main goal of process improvement should always be in balance with upcoming costs. Improvement of customer satisfaction is important, but must be aligned with corporate benefits. At the end of the day it must be realized, that customer benefit is not a goal in itself, it is just a tool to improve the company profit (Jaeck et al., 2007, p. 65). None value-added processes are a waste of time and should be avoided (Jaeck et al., 2007, p. 66).

\section{Conclusion}

Customer orientation is a widely used term. Almost every company claims that customer orientation is a prerequisite for good business and satisfied customers. It is obvious that every company deals with customers, it is one thing every company has in common. Customer orientation is not a new invention, even though the term was first mentioned in 1950. What changed is that companies increasingly realised the importance of customer orientation in times of global and transparent markets, comparable products and intensified competition.

Companies believe that they are customer orientated, but reality appears rather different. Consequently, CRM projects are set up to improve profitability and failure rates of up to $75 \%$ show that there must be a big potential for improvement.

Through a literature review a tool-set of most important tasks was identified to support companies in their effort to be more customer oriented. A clear mission and vision is important in times of change, moving targets and dynamic goals. The definition of customer orientation needs to be clear. Everyone within the company has to know how to deal with the customer. Corporate culture reflects how the company deals with conflicts, what kind of failure culture is lived. Customers observe non-verbal communication and buy less if they think something is not coherent. Customer orientation needs a clear commitment from leaders in words and actions. Human resources and financial resources are limited and need a careful handling. Hence it is not possible to support all customers with the same effort, a concept for a differentiated treatment must be established. Whenever processes have to be changed within an organization, people are involved. Change management prepares employees for upcoming difficulties and challenges that may arise due to necessary changes. Employees of all involved departments need to collaborate for a joint objective, a greater external coherence. For the long-term endeavour customer orientation, training for employees should focus more on attitude than on skills. Employees should thus be encouraged to a commitment to customer service.

Finally, internal key processes have to be reviewed and evaluated whether they are delivering customer satisfaction. Established processes need to be adjusted consequently for customer satisfaction.

Source: own research.

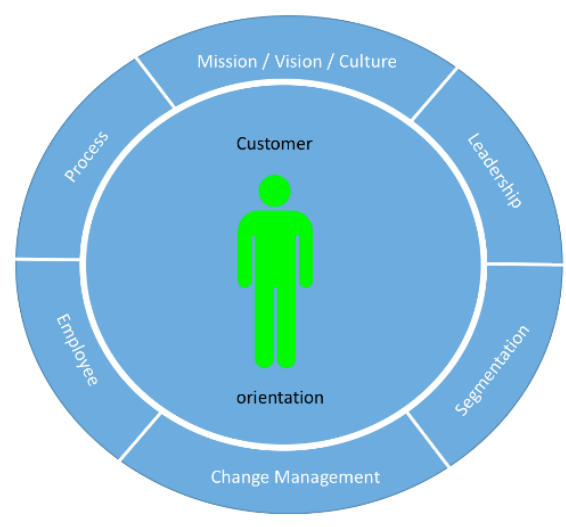

Further research 
With this findings, further investigations could be made to evaluate, whether companies are preparing according identified topics from this paper. In addition, correlation between failed CRM implementations and poor preparation on customer orientation upfront should be examined to provide further insights.

References

[1] Brendel, M. (2002). CRM für den Mittelstand: Voraussetzungen und Ideen für die erfolgreiche Implementierung. Wiesbaden: Gabler.

[2] Bruhn, M. (2002). Integrierte Kundenorientierung: Implementierung einer kundenorientierten Unternehmensführung. Wiessbaden: Gabler.

[3] Bruhn, M. (2016). Kundenorientierung: Bausteine für ein exzellentes Customer Relationship Management (CRM) (5th ed.). München: C.H. Beck.

[4] Gaitanides, M., Raster, M., Rießelmann, D. (1994). Die Synthese von Pro- zessmanagement und Kundenmanagement.In M. Gaitanides, R, Scholz, A. Vrohlings, M. Raster (Ed.): Prozessmanagement Konzepte, Umsetzungen und Erfahrungen des Reengineering (pp. 207-224). München/Wien, S. 207-224.

[5] Gent R., Kempster G. (2002). Leadership and Management. In M. Melling, J. Littele (Ed.), Building a Successful Customer-service Culture. A guide for library and Information managers (pp. 53-73). London: facet.

[6] Hammer, M., Champy, J. (1994). Business Reengineering - die Radikalkur für das Unternehmen (2nd ed.). Frankfurt/New York.

[7] Hanning, G., Krumm, F. (2010). Entwicklung der Mitarbeiterzufriedenheit als Einflussfaktor auf die Kundenzufriedenheit. In F. Keuper, B. Hogenschurz (Ed.), Professionelles Sales \& Service Management: Vorsprung durch konsequente Kundenorientierung (pp. 467-500) (2nd ed.). Wiesbaden: Gabler.

[8] Huldi, C. (2007). CRM - nach der Läuterung eine neue Erkenntnis: Kundenwert versus emotionales CRSM. In M. Hubschneider, K. Sibold, K. (Ed.), CRM - Erfolgsfaktor Kundenorientierung (pp. 107-113) (2nd ed.). München: Haufe.

[9] Keuper, F. (2010). Die Implosion des Market-based View. In F. Keuper, B. Hogenschurz, B. (Ed.), Professionelles Sales \& Service Management: Vorsprung durch konsequente Kundenorientierung (pp. 3-45) (2nd ed.). Wiesbaden: Gabler.

[10] Kreysch, W. (1999). Qualitätsmanagement in der medizinischen Versorgung. In W. Masing (Ed.) Handbuch Qualitätsmanagement (pp. 869-889) (4th ed.). München/Wien.

[11] Jaeck, H.F., Merzenich, M., Wilde, K.D. (2007). Konsequente Kundenorientierung: Optimierung kundenbezogener Geschäftsprozesse. In M. Hubschneider, K. Sibold, K. (Ed.), CRM - Erfolgsfaktor Kundenorientierung (pp. 55-69) (2nd ed.). München: Haufe.

[12] Künzel, H. (2002). Mit interner Kundenzufriedenheit zur externen Kundenbindung: kompromisslose Kundenorientierung als Erfolgsfaktor. München Wien: Hanser.

[13] Newell, F. (2000). Loyalty.com. Customer Relationship Management in the New Era of Marketing. New York: McGraw-Hill.

[14] Nwankwo, Sonny (1995). Developing a customer orientation. Journal of Consumer Marketing, 12 Issue: 5,5-15. doi: $10.1108 / 07363769510103856$

[15] Ose, D. (2011). Patientenorientierung im Krankenhaus. Wiesbaden: VS Research.

[16] Pluse, M.J., Craven, A. (2002). Human resource planning. In M. Melling, J. Littele (Ed.), Building a Successful Customer-service Culture. A guide for library and Information managers (pp. 53-73). London: facet.

[17] Reinartz, W., Kumar, V. (2002) The mismanagement of customer loyalty. United States: Harvard Business Review.

[18] Rosenkranz, F. (2002). Geschäftsprozesse - Modell- und computergestützte Planung. Berlin.

[19] Schimmel-Schloo, M. (2007). CRM aus Kundensicht: Was Kunden heute wollen - und warum CRM dabei helfen kann. In M. Hubschneider, K. Sibold, K. (Ed.), CRM - Erfolgsfaktor Kundenorientierung (pp. 33-38) (2nd ed.). München: Haufe.

[20] Schneider, W. (2008). Profitable Kundenorientierung durch Customer Relationship Management (CRM): wertvolle Kunden gewinnen, begeistern und dauerhaft binden, München: Oldenbourg.

[21] Schwarz, S. (2010). Entwicklung der Mitarbeiterzufriedenheit als Einflussfaktor auf die Kundenzufriedenheit. In F. Keuper, B. Hogenschurz (Ed.), Professionelles Sales \& Service Management: Vorsprung durch konsequente Kundenorientierung (pp. 501-535) (2nd ed.). Wiesbaden: Gabler. 
[22] Utzig, B. P (1997). Kundenorientierung strategischer Geschäftseinheiten: Operationalisierung und Messung. Wiesbaden: Gabler.

[23] Winkelmann, P., (2007). CRM in einem Spannungsfeld zwischen operativem Erfolgsdruck und strategischer Verantwortung. In M. Hubschneider, K. Sibold, K. (Ed.), CRM - Erfolgsfaktor Kundenorientierung (pp. 19-26) (2nd ed.). München: Haufe.

[24] Winters, P. (2014). Customer Strategy. Aus Kundensicht denken und handeln. Freiburg: Haufe. 
